\title{
Mathematical Modeling and Computational Analysis of Underwater Topography with Global Positioning and Echo Sounder Data
}

\author{
Satoshi Iwakami1, Masahiko Tamega1, Masahide Sanada', Michiaki Mohri', \\ Yoshitaka Iwakami', Naoki Okamoto' ${ }^{1}$, Ryousuke Asou', Shuji Jimbo², Masaji Watanabe ${ }^{3}$ \\ ${ }^{1}$ Earth Rise Company, Inc., Okayama, Japan \\ ${ }^{2}$ Visiting Researcher, Okayama University, Okayama, Japan \\ ${ }^{3}$ Specially Appointed Professor, Okayama University, Okayama, Japan \\ Email: watan-m@okayama-u.ac.jp
}

How to cite this paper: Iwakami, S., Tamega, M., Sanada, M., Mohri, M., Iwakami, Y., Okamoto, N., Asou, R., Jimbo, S. and Watanabe, M. (2021) Mathematical Modeling and Computational Analysis of Underwater Topography with Global Positioning and Echo Sounder Data. Journal of Applied Mathematics and Physics, 9, 1171-1179.

https://doi.org/10.4236/jamp.2021.95080

Received: May 7, 2021

Accepted: May 28, 2021

Published: May 31, 2021

\begin{abstract}
This study focuses on change of topography in a water area. Output data from a GPS unit and an echo sounder data were incorporated into analysis for construction of underwater topography. Comparison of two data sets lead to conclusion concerning sedimentation during period from January 2020 to January 2021.
\end{abstract}

\section{Keywords}

Underwater Topography, RTK-GPS, Echo Sounder

\section{Introduction}

Recent disastrous heavy rain events and floods caused severe damages including human damages and house damages. Those include 119 fatalities and 213 totally destroyed houses due to 2018 Japan floods (July 2018) [1], 104 fatalities and 3308 totally destroyed houses due to Typhoon 19 (Hagibis, October 2019) and subsequent heavy rain events [2], and 84 fatalities and 1621 totally destroyed houses due to July 2020 heavy rain disaster [3]. As the climate change progresses such disastrous heavy rain events and floods may occur more frequently, and it is important to establish reliable sources of information concerning land water areas such as rivers, reservoirs, and coastal areas.

This study focuses on construction of underwater topography based on data obtained in field measurement. Apparatuses including a RTK-GPS (real time kinematic global positioning system) in VRS (virtual reference station) mode 
and an echo sounder were used in measurement conducted in Kojima Lake, Okayama Prefecture, Japan. Measurement was conducted on September $28^{\text {th }}$, 2019 , October $4^{\text {th }}, 2019$, December $25^{\text {th }}, 2019$, January $6^{\text {th }}, 2020$, December $26^{\text {th }}$, 2020, January $27^{\text {th }}, 2021$, March $17^{\text {th }}, 2021$, and March $20^{\text {th }}, 2021$ [4] [5] [6] [7]. Previous studies developed numerical techniques to construct surfaces based on data. Those techniques were applied to data sets obtained in the field measurement for construction of surfaces representing underwater topography. Numerical results show sedimentation during period from January 2020 to January 2021.

\section{Application of Numerical Techniques to Data Sets}

Numerical techniques developed in previous studies [4] [5] [6] [7] were reapplied to two data sets. One data set, which we call data set 1 , consisted of results of measurement conducted on September $28^{\text {th }}, 2019$, October $4^{\text {th }}, 2019$, December $25^{\text {th }}, 2019$, and January $6^{\text {th }}, 2020$. The other data set, which we call data set 2 , consisted of results of measurement conducted on December $26^{\text {th }}, 2020$, January $27^{\text {th }}, 2021$, March $17^{\text {th }}, 2021$, and March $20^{\text {th }}, 2021$.

The Gauss-Krüger projection transformed latitude components and longitude components of GPS data to $x y$ components of a rectangular coordinate. Combination of those components with vertical components including output results from an echo sounder leads to three dimensional data that lay in an underwater topography. In particular, $z$ component of three dimensional data $\left(x_{j}, y_{j}, f_{j}\right), j=1,2,3, \ldots$ are given by $f_{j}=h_{j}-d_{j}-z_{0}-L$, where $h_{j}$ is the GPS antenna height, $d_{j}$ is the distance between the oscillator of echo sounder and the bottom, $z_{0}$ is the geodetic height of the mean sea level, and $L$ is the distance between the antenna and the oscillator. Figure 1 shows three dimensional data of Kojima Lake topographic data.

An underwater topography was represented by a piecewise linear function defined on a triangular mesh. An initial triangular mesh $T_{0}$ that contains GPS tracks was set in an $x y$ plane. A sequence of triangular meshes $T_{0}, T_{1}, T_{2}, \ldots$ were constructed from the initial mesh. A triangular mesh $T_{l}(l \geq 1)$ in the sequence was constructed by dividing each element of $T_{l-1}$ into four congruent triangles. Figure 2 shows an initial triangular mesh $T_{0}$. Figure 2 also shows an approximate outline of Kojima Lake based on data obtained with an online software [8].

Suppose that triangular mesh $T_{l}$ consists of $m$ elements $E_{1}, E_{2}, \ldots, E_{m}$, and $n$ nodes $\left(x_{1}, y_{1}\right),\left(x_{2}, y_{2}\right), \ldots,\left(x_{n}, y_{n}\right)$, that elevation of topography $z_{i}$ at node $\left(x_{i}, y_{i}\right)$ is given for $i=1,2, \ldots, n$, and that an element $E_{k}$ contains $p$ data $\left(x_{j}, y_{j}, f_{j}\right), j=1,2,3, \ldots, p$, and that coordinates of vertices of $E_{k}$ are $\left(x_{1}, y_{1}\right)$, $\left(x_{2}, y_{2}\right)$, and $\left(x_{3}, y_{3}\right)$. Note that $x y$ coordinates of the first three data are those of the vertices of $E_{k}$, and that $f_{1}, f_{2}$ and $f_{3}$ are elevations at the vertices $\left(x_{1}, y_{1}\right),\left(x_{2}, y_{2}\right)$, and $\left(x_{3}, y_{3}\right)$, respectively. Consider a linear function $z=a x+b y+c$ such that the values of coefficients $a, b$, and $c$ are those that minimize the square sum 
Data set 1

Sep. 28, 2019

Oct. 4, 2019

Dec. 25, 2019

Jan. 6,2020

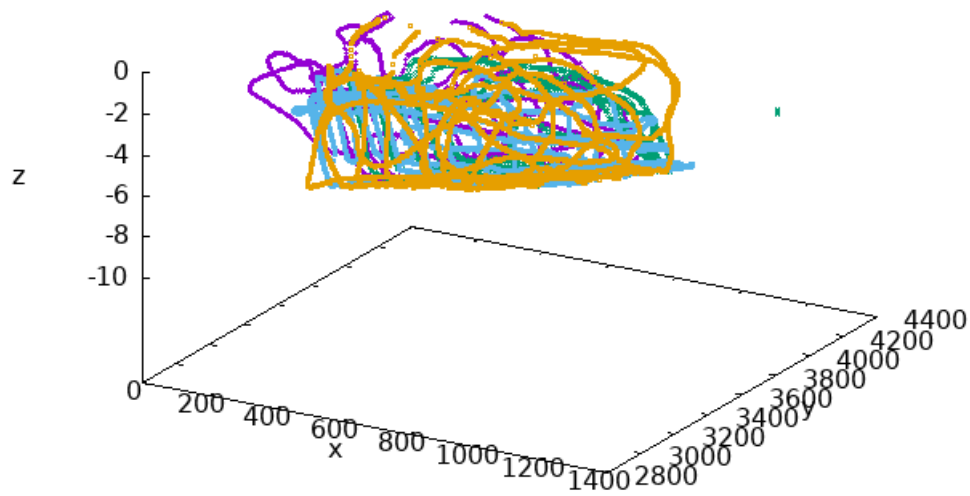

Data set 2

Dec. 26, 2020

Jan. 27, 2021

Mar. 17, 2020

Mar. 20, 2021

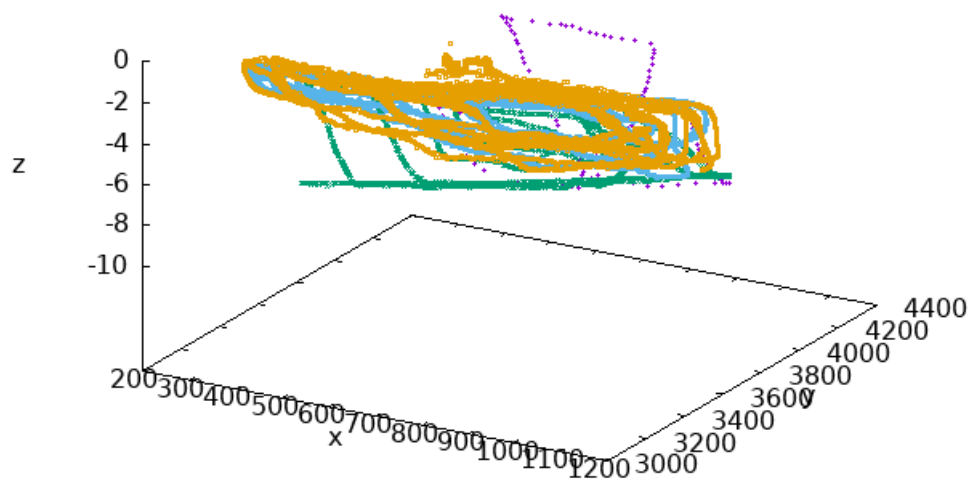

Figure 1. Three dimensional topographic data of Kojima Lake.

Mesh 0: Number of nodes 20, Number of elements 24

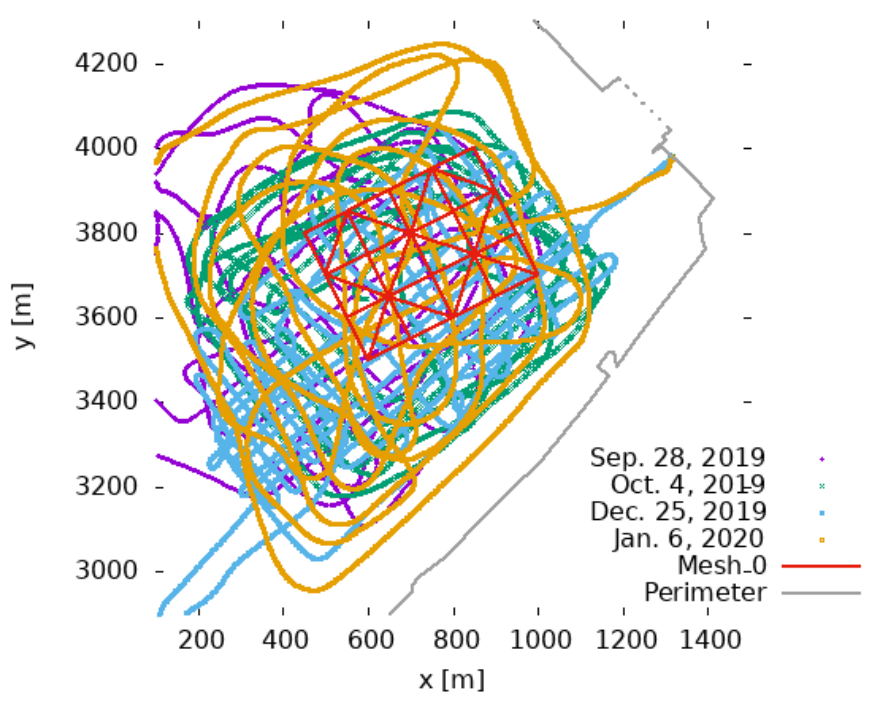


Mesh 0: Number of nodes 20, Number of elements 24

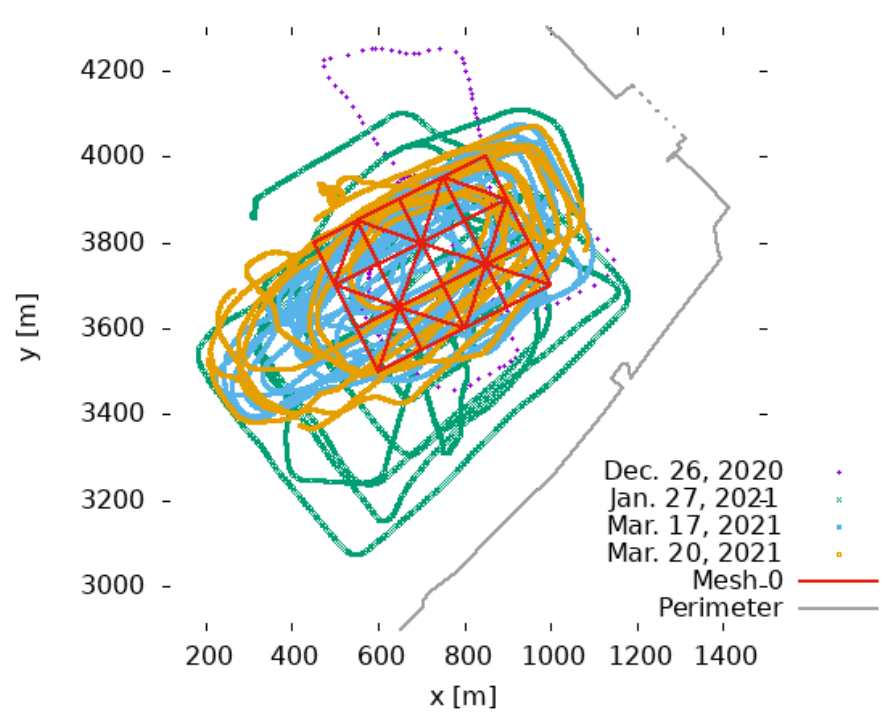

Figure 2. Initial mesh. Three dimensional topographic data are also shown.

$$
\left[f_{1}-\left(a x_{1}+b y_{1}+c\right)\right]^{2}+\cdots+\left[f_{p}-\left(a x_{p}+b y_{p}+c\right)\right]^{2}
$$

Once those coefficients are evaluated, value of $f_{1}$ is updated, that is, $f_{1}=a x_{1}+$ $b y_{1}+c$. With this new value of $f_{1}$, values of coefficients $a, b$, and $c$ that minimize the square sum (1) are updated and the value of $f_{2}$ is updated with equation $f_{2}=$ $a x_{2}+b y_{2}+c$. With those new values of $f_{1}$ and $f_{2}$, values of coefficients $a, b$, and $c$ that minimize the square sum (1) are updated, and the value of $f_{3}$ is updated with equation $f_{3}=a x_{3}+b y_{3}+c$. After those operations are completed $E_{k}$, the operations are repeated for the element $E_{k+1}$. One cycle of iterations is completed for the triangular mesh $T_{l}$ when $k$ reaches $m, Z$ component or elevation associated with the $n$ nodes, $z_{1}, z_{2}, \ldots, z_{n}$ are obtained.

Denote by $\boldsymbol{Z}_{q}=\left(z_{1}^{q}, z_{2}^{q}, \ldots, z_{n}^{q}\right)$ the $n$ dimensional vector whose components are elevation associated with $n$ nodes after $q$ iterations. The iteration is terminated when the residual becomes less than $\varepsilon$, that is

$$
\left\|\boldsymbol{Z}_{q}-\boldsymbol{Z}_{q-1}\right\|=\left[\left(z_{1}^{q}-z_{1}^{q-1}\right)^{2}+\cdots+\left(z_{n}^{q}-z_{n}^{q-1}\right)^{2}\right]^{1 / 2}<\varepsilon .
$$

Values of initial elevation in $T_{0}$ are all set equal to 0 , and values of initial elevation for $T_{l}$ are obtained from values of final elevation for $T_{l-1}$. Figure 3 and Figure 4 show surfaces obtained with $\varepsilon=0.75$. The results shown in Figure 3 and Figure 4 lead to sedimentation during period from January 2020 to January 2021 (Figure 5).

\section{Discussion}

A triangular mesh is set in a part of region covered the triangular mesh shown by Figure by Figure 2 and numerical procedures described in the previous section were repeated. Figure 6 shows the initial mesh. Figure 7 shows the 
Iteration count: 20
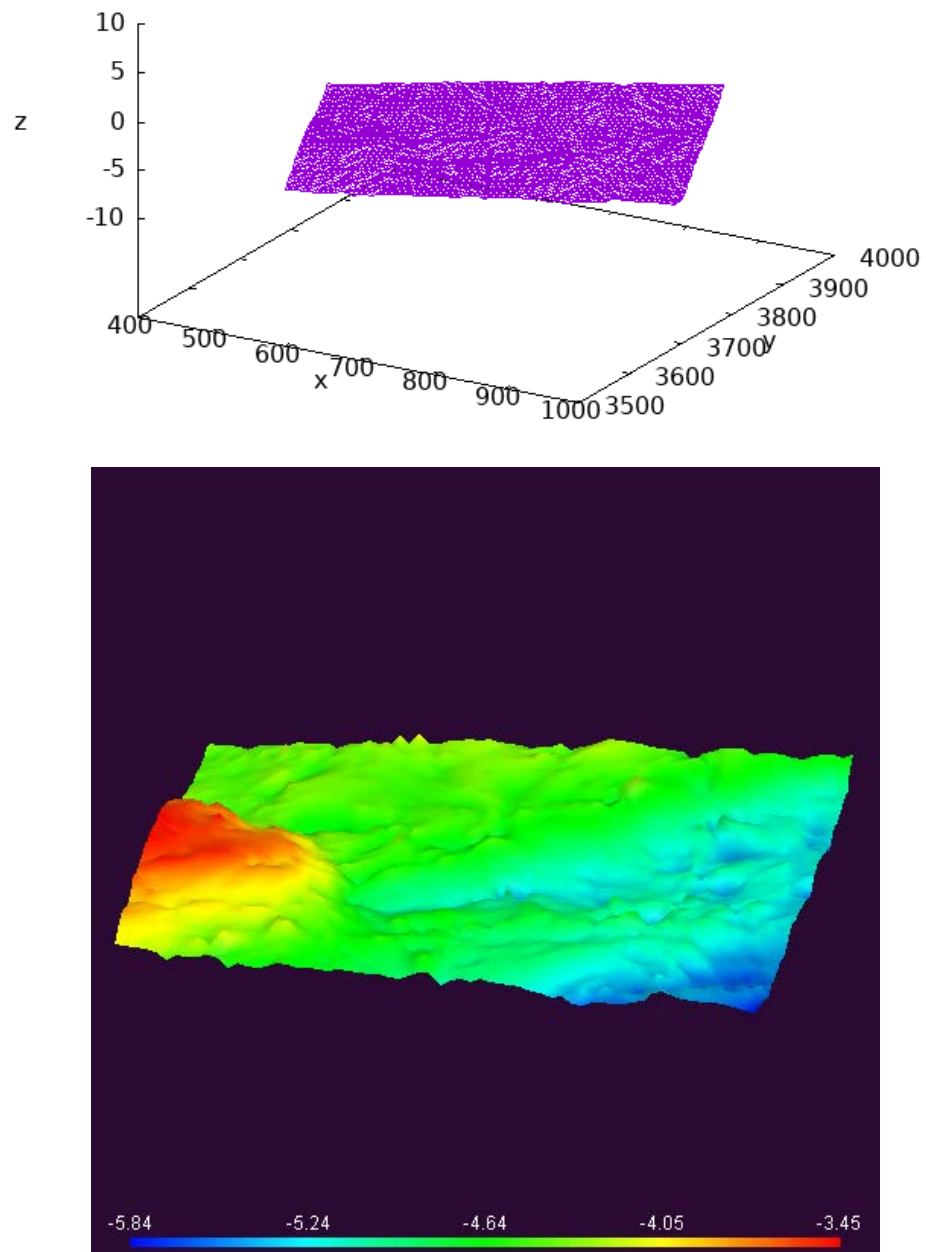

Figure 3. Surface over $T_{4}$ based on data set 1 with $\varepsilon=0.75$, wireframe representation (top), surface with color according to elevation (color).

Iteration count: 40








Figure 4. Surface over $T_{4}$ based on data set 2 with $\varepsilon=0.75$, wireframe representation (top), surface with color according to elevation (bottom).
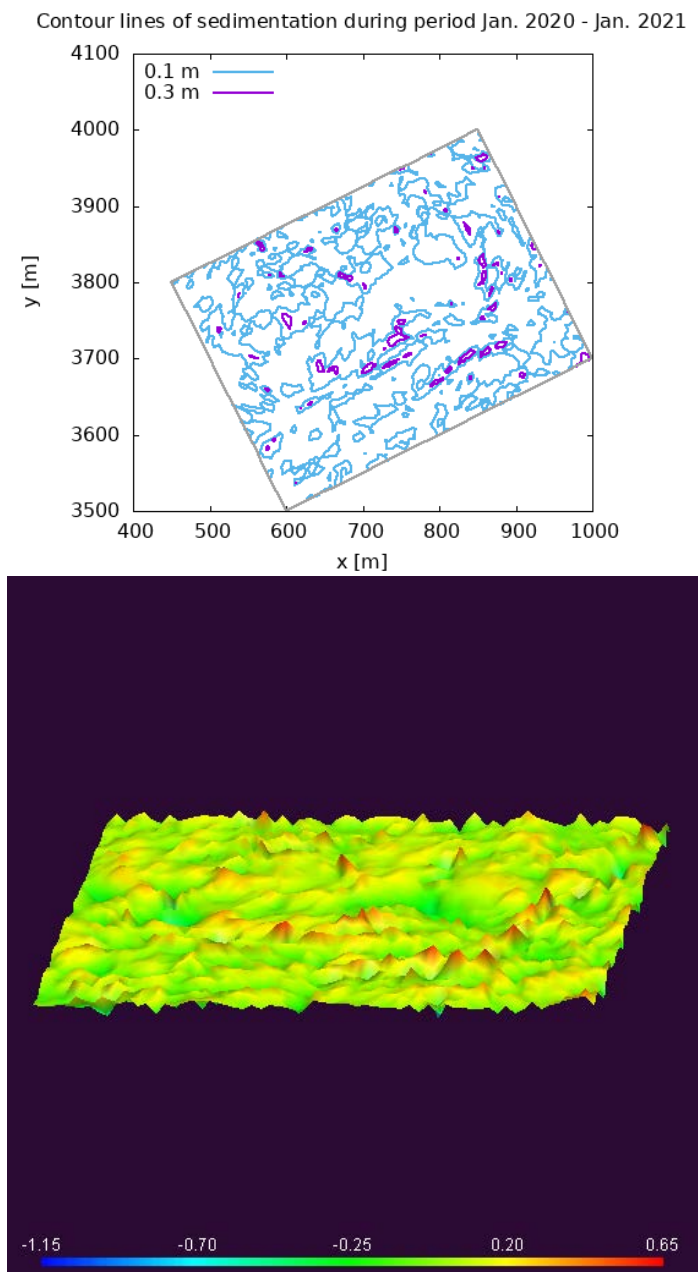

Figure 5. Sedimentation over region over the region covered by the initial mesh shown by Figure 2 during period from January 2020 to January 2021, contour lines $z=0.1$ [m] and $z=0.3[\mathrm{~m}]$ (top), sedimentation with color according to amount (bottom). 
Mesh 0: Number of nodes 6, Number of elements 4



Mesh 0: Number of nodes 15, Number of elements 16



Figure 6. Initial mesh. Three dimensional topographic data are also shown.

sedimentation during period from January 2020 to January 2021.

The area of region covered by the initial mesh shown by Figure 2 is approximately $150,000 \mathrm{~m}^{2}$, and the total sedimentation over the equal to region is approximately $5700.569784 \mathrm{~m}^{3}$. It follows that average increase in elevation of underwater topography over the region is $0.038004 \mathrm{~m}$. The area of region covered by the initial mesh shown by Figure 6 is approximately $25,000 \mathrm{~m}^{2}$, and the total sedimentation over the equal to region is approximately $1508.789762 \mathrm{~m}^{3}$. It follows that average increase in elevation of underwater topography over the region is $0.060352 \mathrm{~m}$.

Major sources of water in Kojima Lake are inflow flow from two rivers Kurashiki River and Sasagase River. Kojima Lake was separated from Kojima Bay by embankment. There are six gates set on the embankment (Figure 2). The water 




Figure 7. Sedimentation over the region covered by the initial mesh shown by Figure 6 during period from January 2020 to January 2021, contour lines $z=0.1$ [m] and $z=0.3[\mathrm{~m}]$ (top), sedimentation with color according to amount (bottom).

level of Kojima Lake is controlled by discharge of water through the gates into Kojima bay during low tide. A possible reason for higher sedimentation over the region shown by Figure 7 is stronger effect of flow generated by the discharge.

\section{Funding}

This study was partly supported by a 2020 research grant from the Public Interest Incorporated Foundation Wesco Promotion of Learning Foundation.

\section{Conflicts of Interest}

The authors declare no conflicts of interest regarding the publication of this paper. 


\section{References}

[1] Ministry of Land, Infrastructure, Transport and Tourism (2018) Summary and Characteristic of Damage in 2018 Japan Floods. (In Japanese) https://www.mlit.go.jp/river/shinngikai_blog/hazard_risk/dai01kai/dai01kai_siryou 2-1.pdf

[2] Cabinet Office, Government of Japan (2020) Situation of Damages and So Forth Concerning 2019 Typhoon 19 as of April 10 ${ }^{\text {th }}, 2020$, 9:00. (In Japanese) http://www.bousai.go.jp/updates/r1typhoon19/pdf/r1typhoon19_45.pdf

[3] Cabinet Office, Government of Japan (2020) Damage Situation and So Forth Concerning July_2020 Heavy Rain Disaster as of January $7^{\text {th }}, 2020,14: 00$. (In Japanese) http://www.bousai.go.jp/updates/r2_07ooame/pdf/r20703_ooame_40.pdf

[4] Iwakami, S., Tamega, M., Jimbo, S. and Watanabe, M. (2019) Numerical Techniques for Underwater Topographic Measurement with GPS and Echo Sounder. International Journal of Information System \& Technology, 3, 81-85. http://ijistech.org/ijistech/index.php/ijistech/article/view/37

[5] Iwakami, S., Tamega, M., Sanada, M., Mohri, M., Iwakami, Y., Jimbo, S. and Watanabe, M. (2020) Study of Underwater Topography Change with Measurement and Analysis. Journal of Physics: Conference Series, 1641, Article ID: 012003. https://iopscience.iop.org/article/10.1088/1742-6596/1641/1/012003/pdf https://doi.org/10.1088/1742-6596/1641/1/012003

[6] Iwakami, S., Tamega, M., Sanada, M., Mohri, M., Iwakami, Y., Okamoto, N., Jimbo, S. and Watanabe, M. (2021) Study on Change of Topography in Water Area with Field Measurement. Journal of Geoscience and Environmental Protection, 9, 221-226. https://www.scirp.org/journal/paperinformation.aspx?paperid=109431

[7] Iwakami, S., Tamega, M., Sanada, M., Mohri, M., Iwakami, Y., Okamoto, N., Asou, R., Jimbo, S. and Watanabe, M. (2021) Numerical Study of Underwater Topography with Measurement Data. 2nd International Conference on Advanced Information Scientific Development (ICAISD). https://doi.org/10.1088/1742-6596/1641/1/012003

[8] Latitude-Longitude Map.

https://fukuno.jig.jp/app/printmap/latlngmap.html 